\title{
Failure phenomena in multi-fibre model composites: Part 1. An experimental investigation into the influence of fibre spacing and fibre-matrix adhesion
}

Citation for published version (APA):

van den Heuvel, P. W. J., Bruggen, van der, Y. J. W., \& Peijs, A. A. J. M. (1996). Failure phenomena in multifibre model composites: Part 1. An experimental investigation into the influence of fibre spacing and fibre-matrix adhesion. Composites. Part A: Applied Science and Manufacturing, 27(9), 855-859.

https://doi.org/10.1016/1359-835X(96)00023-1

DOI:

10.1016/1359-835X(96)00023-1

Document status and date:

Published: 01/01/1996

Document Version:

Publisher's PDF, also known as Version of Record (includes final page, issue and volume numbers)

\section{Please check the document version of this publication:}

- A submitted manuscript is the version of the article upon submission and before peer-review. There can be important differences between the submitted version and the official published version of record. People interested in the research are advised to contact the author for the final version of the publication, or visit the $\mathrm{DOI}$ to the publisher's website.

- The final author version and the galley proof are versions of the publication after peer review.

- The final published version features the final layout of the paper including the volume, issue and page numbers.

Link to publication

\footnotetext{
General rights

- You may freely distribute the URL identifying the publication in the public portal. follow below link for the End User Agreement:

www.tue.nl/taverne

\section{Take down policy}

If you believe that this document breaches copyright please contact us at:

openaccess@tue.nl

providing details and we will investigate your claim.
}

Copyright and moral rights for the publications made accessible in the public portal are retained by the authors and/or other copyright owners and it is a condition of accessing publications that users recognise and abide by the legal requirements associated with these rights.

- Users may download and print one copy of any publication from the public portal for the purpose of private study or research.

- You may not further distribute the material or use it for any profit-making activity or commercial gain

If the publication is distributed under the terms of Article 25fa of the Dutch Copyright Act, indicated by the "Taverne" license above, please 


\title{
Failure phenomena in multi-fibre model composites: Part 1. An experimental investigation into the influence of fibre spacing and fibre-matrix adhesion
}

\author{
P. W. J. van den Heuvel, Y. J. W. van der Bruggen and T. Peijs* \\ Eindhoven University of Technology, Centre for Polymers and Composites, PO Box 513, \\ 5600 MB Eindhoven, The Netherlands
}

\begin{abstract}
Multi-fibre model composites were used to study the fracture process of carbon/epoxy composites in uniaxial tension. The investigations were focused on experimentally determining the influence of interfibre spacing and fibre-matrix adhesion on the amount of fibre-fibre interaction taking place, i.e. fibre failure due to increased stress concentrations caused by a fracture site in an adjacent fibre, visible through the alignment of fracture sites. In addition to in situ microscopic observations, a quantitative criterion for fibre-fibre interaction was employed. Results showed that, in case of good fibre-matrix adhesion, fibre-fibre interaction takes place at interfibre spacings of less than nine diameters. Furthermore, it was found that the level of fihre surface treatment significantly influences the amount of aligned fracture sites.
\end{abstract}

(Keywords: multi-fibre model composites; fibre-fibre interaction; fibre-matrix adhesion)

\section{INTRODUCTION}

Failure in fibre-reinforced materials is a sequence of microscopic events (e.g. fibre rupture, matrix cracking, debonding), each of which affects the stress state of the material. Such a failure process proceeds until a critical condition is reached, resulting in global failure of the composite. The interaction between the fibre and the matrix is generally accepted as a predominant parameter in controlling micromechanical failure processes and, consequently, macroscopic mechanical properties of fibre-reinforced materials such as strength and durability. Even in the case of longitudinal loading conditions, where strength is mainly controlled by the stiff fibres, experiments on unidirectional carbon/epoxy laminates showed significant and in some cases contradictory effects of fibre-matrix adhesion on the longitudinal composite strength ${ }^{1-4}$. For example, for carbon/epoxy composites, Madhukar and Drzal ${ }^{1}$ and Ivens et al..$^{2}$ reported the longitudinal tensile strength to be highest at intermediate surface treatment levels. Bader et $\mathrm{al}^{3}$, on the other hand, reported the longitudinal composite strength to be

* To whom correspondence should be addressed lowest at intermediate surface treatment levels. All these macroscopic effects originate from microfeatures such as the statistical distribution of fibre strength, fibrematrix interface strength, interphase (yield) strength, stress concentrations in neighbouring fibres around a fibre break, and matrix cracks.

The objective of this series of papers is to reveal the influence of some of these microfeatures on the macroscopic failure process of fibre-reinforced composites. Use is made of microcomposite model systems consisting of several continuous carbon fibres aligned parallel at a predefined interfibre spacing in an epoxy dumb-bell shaped tensile bar. It has been shown in the past that such microcomposite model systems are very useful in analysing microscopic fibre-fibre interaction, i.e. fibre failure due to stress concentrations resulting from a fibre break in a neighbouring fibre ${ }^{5-9}$. In this paper we investigate the influence of fibre-matrix adhesion and fibre spacing on the level of fibre-fibre interaction. This is done in both a qualitative and a quantitative way. In order to quantify the level of fibre-fibre interaction an interaction criterion is introduced, giving a clear view of the influence of interfibre spacing and fibre-matrix adhesion on the fibre-fibre interaction. 


\section{EXPERIMENTAL}

\section{Materials}

Unsized intermediate-modulus carbon fibres (Courtaulds, Apollo IM 43-750) of three different oxidative surface treatment levels were used: (1) standard untreated fibres, which received the commercial treatment $(100 \%)$; (2) untreated fibres $(0 \%)$; and (3) an intermediate treatment level $(10 \%)$. The resin consisted of a common diglycidyl ether of bisphenol-A (DGEBA) Epoxy (Ciba Geigy, LY556) and a stoichiometric amount of poly(oxypropylene) triamine curing agent (Texaco, Jeffamine T-403).

\section{Method}

Multi-fibre composites (MFC) samples were preparcd by positioning five fibres parallel at a predefined interfibrc spacing using a tcchnique developed by Wagner and Steenbakkers ${ }^{6}$. The interfibre distance was varicd from three to 20 fibre diameters, i.e. 15 to $100 \mu \mathrm{m}$. To exclude the influence of differences in fibre pretension on the failure process, a weight of $150 \mathrm{mg}$ was attached to each fibre. After adjusting the interfibre spacing, the fibres were glued in the cavity of a dogboneshaped silicone mould using fast-setting epoxy cement. Subsequently, pre-heated and degassed epoxy resin $\left(60^{\circ} \mathrm{C}, 400\right.$ torr) was carefully injected into the mould, followed by a glass plate and a $3 \mathrm{~kg}$ weight to close the mould. Finally, the samples were cured at room tempcrature for $24 \mathrm{~h}$, and post-cured at $75^{\circ} \mathrm{C}$ for $16 \mathrm{~h}$.

To obtain qualitative information about the failure process, multi-fibre fragmentation tests were performed using a polarized-light microscope equipped with a hand-driven mini tensile tester. The failure phenomena were recorded by means of photography and video. In addition, to obtain quantitative information about the failure process, multi-fibre fragmentation tests were performed on a universal tensile tester (Frank 81565) while monitoring the fragmentation process with an acoustic emission set-up (Physical Acoustic Corporation, Locan AT). The samples were strained at a strain rate of $10^{-4} \mathrm{~s}^{-1}$. The acoustic emission set-up enabled us to determine the saturation stage of the fragmentation process, which is essential in the quantitative context ${ }^{10}$. After testing, the positions of the fibres breaks were registered by hand using a polarized-light microscope.

\section{RESULTS AND DISCUSSION}

\section{Influence of fibre spacing}

The influence of fibre spacing on the failure process was investigated using the commercial treated fibres $(100 \%)$. Figure 1 shows the fragmentation process of a multi-fibre microcomposite with an interfibre spacing of nine fibre diameters, i.e. $45 \mu \mathrm{m}$. As shown in the first micrograph of Figure 1, the first fibre ruptures occur at a (macroscopic) strain level of approximately $1.2 \%$. From
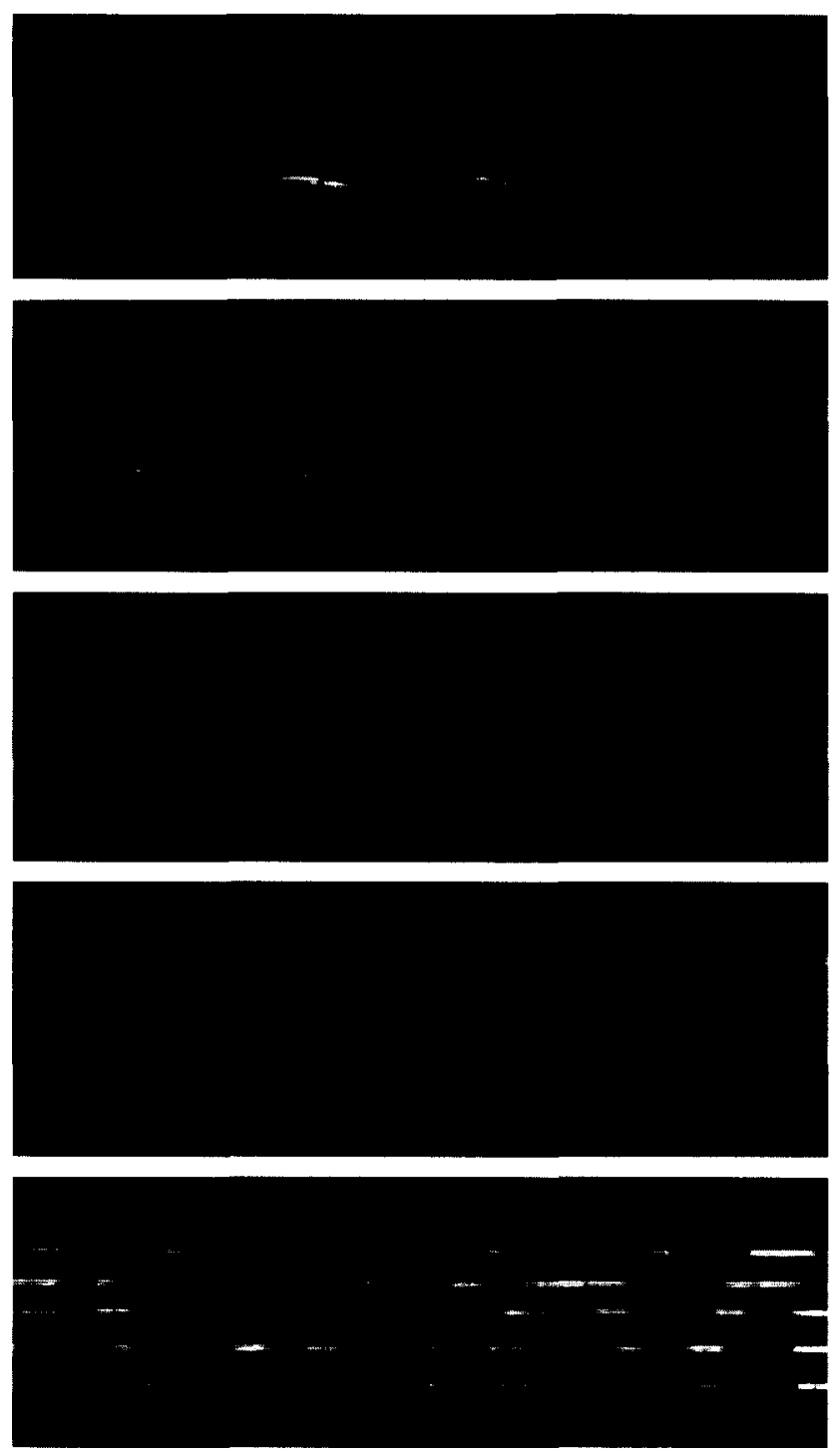

Figure 1 Polarized-light micrographs showing the failure process in a multi-fibre model composite containing five commercially surfacetreated $(100 \%)$ carbon fibres embedded in an epoxy matrix at an interfibre spacing of nine fibre diameters. The applied strains are, from top to bottom: $1.2 \%, 1.5 \%, 2.1 \%, 2.7 \%$ and $4.3 \%$ (failure of specimen)

the birefringence patterns it can be seen that debonding occurs over only a very short length, indicating good fibre-matrix adhesion. The fragmentation process is followed up to saturation, i.e. the point at which the fibres cannot accommodate another break, which occurs at a strain of $2.7 \%$. The final photograph demonstrates the birefringence pattern at the saturation stage after releasing the macroscopic strain. It can be observed that although elastic deformation has disappeared, a significant amount of plastic deformation (i.e. shear yielding) in the matrix has taken place near the fibrematrix interface ${ }^{11}$.

Figure 2 depicts polarized-light micrographs of microcomposites with different interfibre spacings after saturation and unloading of the samples. It is obvious that the distribution of fracture sites is dependent on the interfibre spacing. Samples with fibres separated by 20 fibre diameters clearly show random fibre fracture, whereas samples with an interfibre spacing of three fibre 


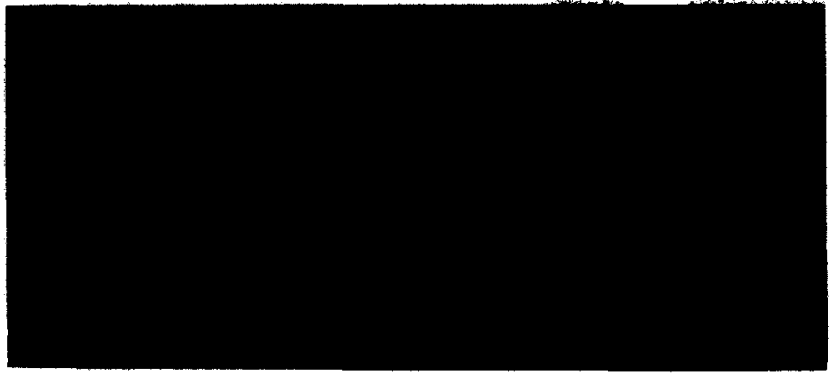

(a)

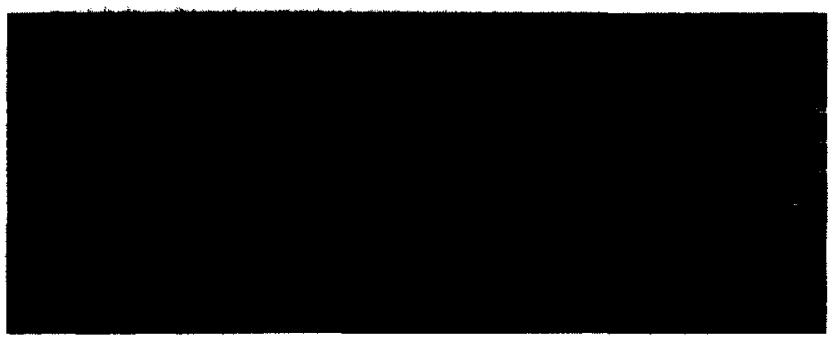

(b)

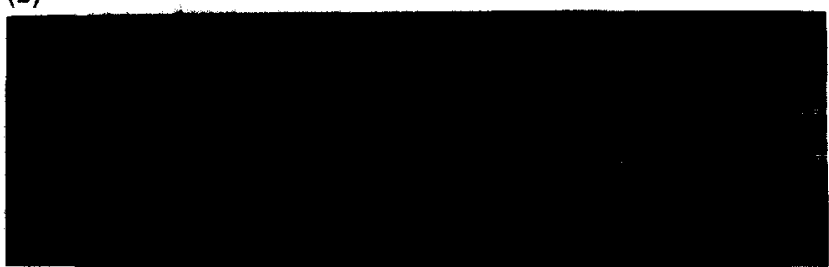

(c)

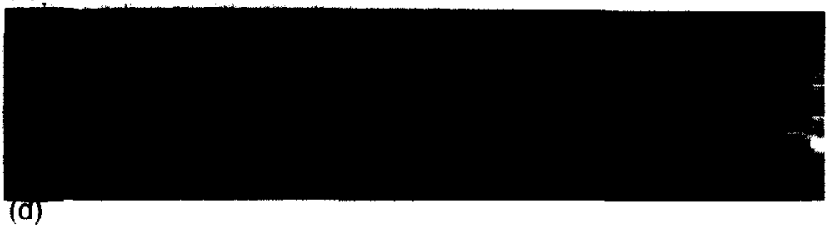

Figure 2 Polarized-light micrographs of microcomposites containing five commercially surface-treated $(100 \%)$ carbon fibres showing the influence of interfibre spacing on the failure process, after complete saturation of the failure process. The interfibre spacings are (a) 20, (b) 9 (c) 7 and (d) 3 fibre diameters

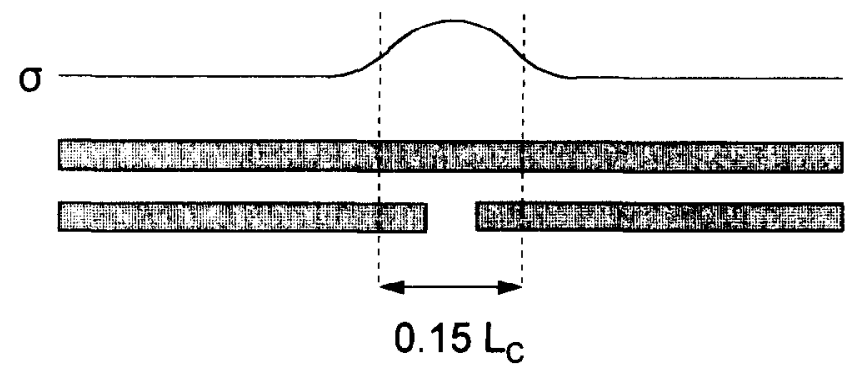

Figure 3 Schematic representation of the interaction criterion

diameters reveal an alignment, or coordination, of fractures in adjacent fibres. This coordinated fracture, i.e. fibre-fibre interaction, indicates that stress concentrations caused by a primary fibre fracture are sufficiently high to cause fracture of the neighbouring fibre in the vicinity of that fracture site, overruling the influence of randomly distributed flaws along the fibre on its strength (see Figure 3).

A quantitative analysis of the distribution of breaks was made by registering all the break positions, followed by grouping the breaks by applying a criterion for the interfibre break distance. As an interaction criterion, we

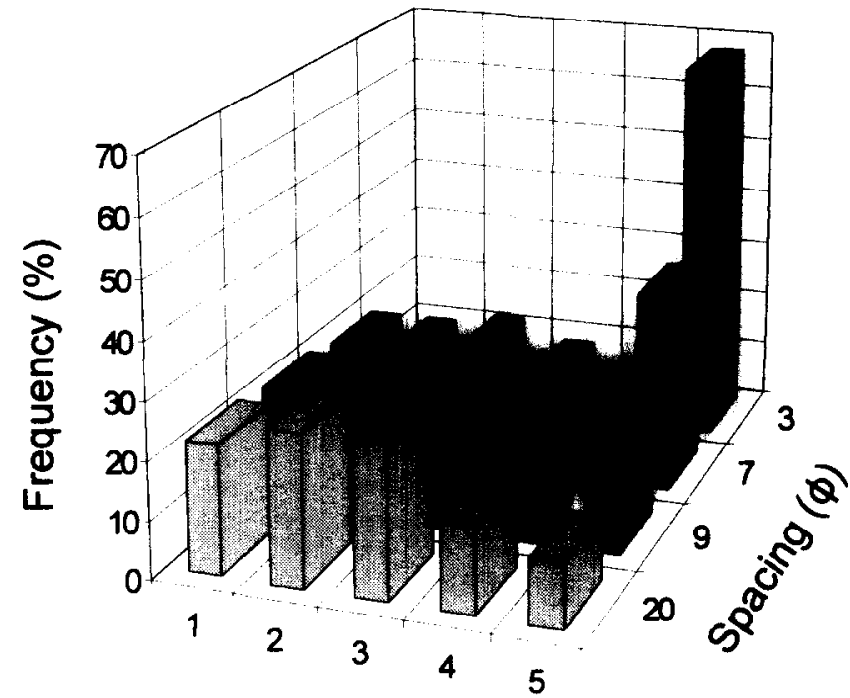

Aligned breaks (-)

Figure 4 Influence of interfibre spacing on the alignment of fibre fracture in a microcomposite containing five commercially surfacetreated $(100 \%)$ carbon fibres in an epoxy matrix

took $15 \%$ of the critical length of each individual sample (see Figure 3). As outlined by Feillard et al. ${ }^{12}$, there is still no commonly accepted way to determine the critical length from the fragment length distribution. Since a well defined determination of the critical length is not crucial in the present context, we arbitrarily took the critical length to equal twice the expected value of a Gamma distribution fitted to the final fragment length distribution. The Gamma distribution was found to fit even the skewed final fragment length distributions of the untreated $(0 \%)$ and intermediate $(10 \%)$ surface-treated fibres well. Finite element analysis showed that this criterion approximately equals the length over which the stress magnification effect, as a result of a primary fibre break, occurs in neighbouring fibres in the case of good fibre-matrix adhesion ${ }^{13}$. The result of such a quantitative analysis is presented in Figure 4. Up to three samples were tested for each interfibre spacing. Figure 4 clearly reveals that a smaller interfibre spacing leads to more aligned fibre ruptures. For example, at an interfibre spacing of three fibre diametcrs, $65 \%$ of the breaks are coordinated with the maximum of five breaks. At increasing interfibre spacing the coordination decreases, i.e. the failure pattern becomes more random and is governed by the flaw distribution on the fibres. The transition from random failure to coordinated failure occurs at an interfibre spacing of approximately nine fibre diameters. Similar results were reported by Jones and DiBenedetto ${ }^{9}$ who, for an AS-4 carbon/epoxy system, observed visually that the transition occurs at a fibre spacing of eight fibre diameters. Generally, it is assumed that the size of the influenced area around a fibre break in the absence of matrix cracks and debonding is five to six fibre diameters large ${ }^{5,6}$, being smaller than our findings. According to analytical calculations $^{14,15}$ the size of the influenced area around a fibre break depends on the stiffness ratio of the fibre and 
the matrix, $E_{\mathrm{f} /} E_{\mathrm{m}}$, where $E_{\mathrm{f}}$ and $E_{\mathrm{m}}$ are the (longitudinal) moduli of the fibre and matrix, respectively. In our experiments this ratio has a value of $81\left(E_{\mathrm{f}}=285 \mathrm{GPa}\right.$, $E_{\mathrm{m}}=3.5 \mathrm{GPa}$ ), classifying our system as stiff. A more flexible matrix will result in poorer stress transfer from the matrix to the fibre and, hence, in a larger ineffective length. Obviously, this will influence the stress concentrations in the neighbouring fibres and, consequently, the size of the influenced area. Furthermore, as will be shown in the following, the size of the influenced area is significantly affected by debonding.

\section{Influence of adhesion}

In Figure 5, polarized-light micrographs are shown for the untreated $(0 \%)$ and the intermediate $(10 \%)$ treated fibres after complete saturation of the failure process. The interfibre spacing is three fibre diameters for both samples. In comparison with the commercial $(100 \%)$ treated fibres, extensive debonding is observed in the untreated case. The intermediate treated fibre is also found to give fibre-matrix debonding, but substantially less than the untreated fibre.

With respect to fracture alignment, it is observed in Figure 5 that the untreated $(0 \%)$ fibre does not display any alignment of fibre breaks, i.e. random failure occurs. The intermediate $(10 \%)$ surface-treated fibre does, however, show some alignment of fibre fractures similar to the case of the commercial $(100 \%)$ treated fibre (see Figure $2 d$ ). These observations are supported in a more quantitative way by Figure 6, in which a coordination plot is given for the three surface treatment levels investigated. For the untreated $(0 \%)$ and intermediate $(10 \%)$ treated carbon fibres the same grouping criterion is applied as for the commercially $(100 \%)$ treated fibre, being $15 \%$ of the critical length of each individual sample. Figure 6 clearly shows that the level of surface treatment significantly influences the level of fibre fracture alignment: the higher the surface treatment level, the higher the level of alignment. Obviously, the low fracture alignment in the case of untreated $(0 \%)$ and intermediate $(10 \%)$ surface-treated fibre can be explained by the amount of fibre-matrix debonding. According to finite element calculations ${ }^{16}$ and laser Raman experiments ${ }^{17}$, an increase in debonded length has a twofold effect on the stress situation in the adjacent fibre: (1) a decrease of the maximum stress concentration in the fibres adjacent to a break, and (2) a shift of this maximum away from the fibre break, i.e. towards a position at the end of the debonded area of the broken fibre. The first effect lowers the possibility of fibre-fibre interaction, i.e. the fracture pattern inherently becomes more random, whereas the second effect causes an adjacent fibre to break due to fibre-fibre interaction at a position away from the initial fibre break, i.e. the fracture process appears to be more random. Importantly, both effects result in a decrease of the fracture alignment, i.e. the fracture pattern becomes more random.

If one wants to determine the influenced area around a

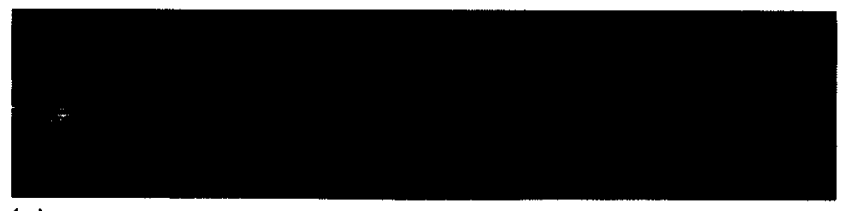

(a)

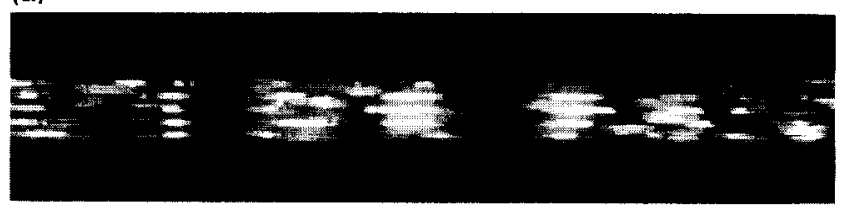

(b)

Figure 5 Polarized-light micrographs of microcomposites containing five carbon fibres showing the influence of fibre surface treatment on the failure patterns, after complete saturation of the failure process. (a) Untreated $(0 \%)$, (b) intermediate treated $(10 \%)$ carbon fibre

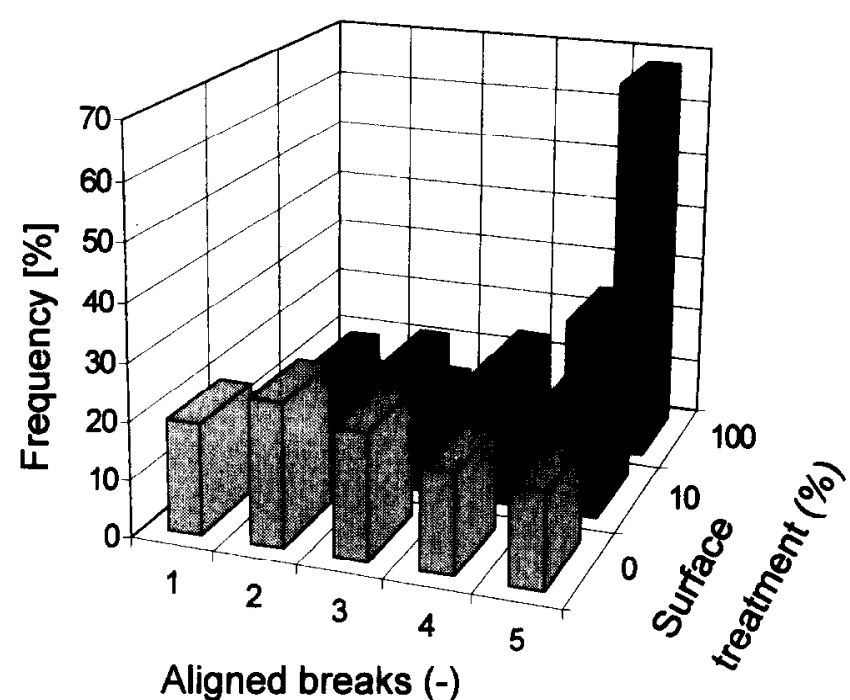

Figure 6 Influence of fibre surface treatment on the alignment of fibre fracture in a microcomposite containing five carbon fibres embedded in an epoxy matrix at an interfibre spacing of three fibre diameters

fibre fracture, i.e. the area in which fibre-fibre interaction takes place, in the case of significant debonding, another interaction criterion has to be applied because of the inherent randomness of fibre fracture. Instead of selecting breaks with respect to both their positions, fibre breaks in the adjacent fibre should now be selected with respect to the end of the debonded area of the broken fibre. In the case of very poor fibre-matrix adhesion, i.e. in the case of untreated $(0 \%)$ carbon fibre, however, this is an impossible task since the debonded areas grow substantially during straining of the MFC sample, disturbing the view at the saturation stage of the fragmentation process (at which the grouping criterion is applied). It is, however, possible to obtain an idea of the size of the influenced area around a broken fibre in the case of debonding, by means of finite element analysis and laser Raman experiments. This is the topic of ongoing research and we hope to be able to report on this in the near future.

\section{CONCLUSIONS}

Multi-fibre carbon/epoxy microcomposites have been 
used to study the influcnce of interfibrc spacing and fibre-matrix adhesion on the failure process. Visual observations showed that in the case of commercially treated carbon fibre, i.e. good fibre-matrix adhesion, coordinated fibre failure-i.e. fibre failure due to increased stress concentrations caused by a fracture site in an adjacent fibre - takes place at interfibre spacings of less than nine fibre diameters. At larger interfibre spacings random failure occurs, i.e. the failure process is governed by the statistical strength distribution of the fibres. In order to quantify these visual observations a fibre-fibre interaction criterion was proposed, being $15 \%$ of the critical length. This criterion confirmed our visual observations.

Furthermore, it was shown that the level of fibre surface treatment significantly influences the level of aligned fibre fracture. Untrcated $(0 \%)$ carbon fibre displays a random failure pattern, whereas intermediate surface-treated carbon fibres show some aligned, or coordinated, fibre fracture. This effect is attributed to the occurrence of fibrc-matrix debonding which will bc addressed in more detail in a forthcoming paper.

\section{ACKNOWLEDGEMENTS}

The authors would like to thank Huntsman N.V. Belgium for supplying the Jeffamine T-403 curing agent. Thanks are also extended to Wilco Verbeeten for performing some of the multi-fibre fragmentation tests.

\section{REFERENCES}

1 Madhukar, M.S. and Drzal, L.T. Fiber-matrix adhesion and its effect on composite mechanical properties: II. Longitudinal $\left(0^{\circ}\right)$ and transverse $\left(90^{\circ}\right)$ tensile and flexure behavior of graphite/ epoxy composites. J. Compos. Mater. 1991, 25, 958

2 Ivens, J., Wevers, M. and Verpoest, I. Influence of carbon fibre surface treatment on composite UD strength. Composites 1994 , 25, 722

3 Bader, M.G., Pickering, K.L., Buxton, A., Rezaifard, A. and Smith, P.A. Failure micromechanisms in continuous carbonfibre/epoxy-resin composites. Compos. Sci. Technol. 1993, 48, 103

4 Norita, T. Matsui, J. and Matsuda, H.S. Effect of surface treatment of carbon fibre on mechanical properties of CFRP. In 'Composite Interfaces' (Eds H. Ishida and J.L. Koenig), North Holland, New York 1986, pp. 123-132

5 Mullin, J., Berry, J.M. and Gatti, A. Some fundamental fracture mechanisms applicable to advanced filament reinforced composites. J. Compos. Mater. 1968, 2, 82

6 Wagner, H.D. and Steenbakkers, L.W. Microdamage analysis of fibrous composite monolayers under tensile stress. J. Mater. Sci. 1989, 24, 3956

7 Wagner, H.D. Characterization of statistical failure in fiber composite monolayers by video microphotography. J. Appl. Polym. Sci., Appl. Polym. Symp. 1991, 47, 111

8 Van den Heuvel, P.W.J. Van der Bruggen, Y.J.W. and Peijs, T. The influence of fibre surface treatment on fibre-fibre interactions in multi-fibre microcomposites. Adv. Compos. Lett. 1994, 3. 197

9 Jones, K.D. and DiBenedetto, A.T. Fiber fracture in hybrid composite systems. Compos. Sci. Technol. 1994, 51, 53

10 Favre, J.P. and Jacques, D. Stress transfer by shear in carbon fibre model composites: Part 1: Results of single-fibre fragmentation tests with thermosetting resin. J. Mater. Sci. 1990, 25, 1373

11 Bascom, W.D. and Jensen, R.M. Stress transfer in single fibre resin tensile tests. J.Adhes. 1986, 19, 219

12 Feillard, P., Désarmot, G. and Favre, J.P. Theoretical aspects of the fragmentation test. Compos. Sci. Technol. 1994, 50, 265

13 Van der Heuvel, P.W.J. and Peijs, T. to be published

14 Wagner, H.D. and Eitan, A. Stress concentration factors in twodimensional composites: effects of material and geometrical parameters. Compos. Sci. Technol. 1993, 46, 353

15 Bader, M.G. Tensile strength of uniaxial composites Sci. Eng. Compos. Mater. 1988, 1. 1

16 Nedele, M.R. and Wisnom, M.R. Stress concentrations factors around a broken fibre in a unidirectional carbon fibre-reinforced epoxy. Composites 1994, 25, 549

17 Van den Heuvel, P.W.J. Young. R.J. and Peijs. T. to be published. 